\title{
Rheological change and degassing during a trachytic Vulcanian eruption at Kilian volcano, Chaîne des Puys, France
}

\author{
MATHIEU COLOMBIER ${ }^{1 *}$; ALAIN BURGISSER ${ }^{2}$; \\ FRANCISCO CÁCERES ${ }^{1}$; TIMOTHY H. DRUITT ${ }^{3}$; LUCIA \\ GURIOLI $^{3}$; KAI-UWE HESS ${ }^{1}$; DIRK MÜLLER ${ }^{1}$; THOMAS \\ SHEA $^{4}$; AND DONALD B. DINGWELL ${ }^{1}$ \\ ${ }^{1}$ Department of Earth and Environmental Sciences, Ludwig- \\ Maximilians-Universität München, Germany \\ *correspondence: mathieu.colombier@min.uni- \\ muenchen.de \\ ${ }^{2}$ Univ. Savoie Mont Blanc, CNRS, IRD, ISTerre, F-73376 Le \\ Bourget du Lac, France \\ ${ }^{3}$ Université Clermont Auvergne -CNRS-IRD, OPGC, \\ Laboratoire Magmas et Volcans, F-63100, Clermont- \\ Ferrand, France \\ ${ }^{4}$ Geology and Geophysics, University of Hawai'i at Mānoa, \\ Honolulu, Hawaii, USA
}

Trachytic silicate melts differ from their calc-alkaline counterparts mostly due to their high crystallization rate, degassing kinetics and low viscosity. Here we study the role of crystallization and degassing on eruptive style during a trachytic Vulcanian eruption at Kilian volcano, France.

We combined chemical, textural and rheological analysis of juvenile lapilli and assessed the evolution of water content during magma ascent via thermogravimetry measurements. Finally, we compared our crystallinity and chemical data to a compilation of crystallization experiments and to thermodynamic modelling using Rhyolite-MELTS [1].

We found that low viscosity, crystal-poor and volatilerich trachytic magma ascended rapidly in the conduit. However, fast crystallization and degassing $\left(\mathrm{H}_{2} \mathrm{O}\right.$ content decreased from 8 to $0.04 \mathrm{wt} \%$ during ascent) could keep pace with this rapid ascent, causing an increase of viscosity by more than 10 orders of magnitude and promoting dome formation. We generalize our findings to trachytic eruptions worldwide (e.g., Hualālai volcano in Hawaii) and show that rapid rheological changes may lead to a broader range of eruptive styles than for calc-alkaline magmas. In particular, this behaviour may shorten the cyclicity of viscous-brittle transitions and explosive pulses during Vulcanian eruptions, with potential implications for volcanic hazards in highly populated areas nearby trachytic volcanoes.

[1] Gualda et al (2012) J. Petrol. 53, 875-890. 